\title{
COMPARAÇÃO DAS VAZÕES DE PROJETO PELO MÉTODO RACIONAL E MÉTODO TEMPO ÁREA PARA BACIAS URBANAS DO MUNICÍPIO DE GOIÂNIA - GO
}

\section{COMPARISON OF STREAMFLOW FOR RATIONAL METHOD AND TIME-AREA METHOD FOR URBAN BASINS IN THE CITY OF GOIÂNIA - GO}

\author{
Ana Carolina Seibt ${ }^{1}$; Duane Izabel Barbosa ${ }^{2}$; Aline de Arvelos Salgado ${ }^{3}$, \\ Klebber T. Martins Formiga ${ }^{4}$
}

Recebido em 01 de agosto de 2012; recebido para revisão em 18 de agosto de 2012; aceito em 23 de agosto de 2012; disponível on-line em 08 de setembro de 2012.

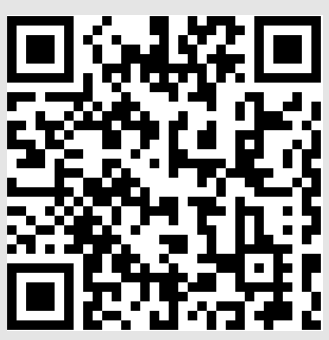

PALAVRAS CHAVES:

Método racional;

Método tempo-área;

Drenagem urbana.

KEYWORDS:

Rational method;

Method time-area;

Urban drainage;

\begin{abstract}
RESUMO: A ineficiência e o sub-dimensionamento de alguns dispositivos de drenagem urbana refletem com precisão, a carência de estudos, quanto às vazões de projeto resultantes de precipitações. O presente trabalho resulta de uma análise comparativa de duas metodologias, método racional e tempo-área, para a determinação das vazões de projeto em bacias. O estudo desenvolveu-se sobre três bacias do município de Goiânia GO com diferentes valores de área de drenagem (Córrego Ruivinho, Mingau e da Cruz). Com os dados da caracterização física da bacia, foi empregado um método de simulação que permitiu a obtenção das chuvas de projeto para diferentes tempos de retorno para as seções exutórias. Os valores encontrados para o método racional praticamente não variaram para as bacias em questão, pode-se dizer que a diferença foi insignificante. Tal estudo demonstra que o método racional, tende a superestimar as vazões de projeto e não devem ser utilizados para bacias superiores a $1 \mathrm{~km}^{2}$ por não considerar a translação na bacia nem a forma da mesma.
\end{abstract}

ABSTRACT: The inefficiency of some devices and undersizing urban drainage accurately reflect the lack of studies, regarding the design flows resulting from rainfall. This work results from a comparative analysis of two methods for determining the flow of design in urban and rural basins. The study was carried out on three basins in the city of Goiânia GO with different values of drainage area (Ruivinho, Mingau e da Cruz). With data from the physical characteristics of the basin was used a simulation method that yielded the design rainfall for different return periods for sections outfall. We then employed the rational methods and time-area to determine the design flow. The values found for the rational method have not varied for the basins in question, one can say that the difference was insignificant. This study demonstrates that the rational method tends to overestimate the flows of the project and should not be used for basins exceeding $1 \mathrm{~km} 2$ for not considering the translation in the basin and the way of it.

\footnotetext{
* Contato com os autores:

1 e-mail : anaseibt@gmail.com (A. C. Seibt)

Aluna de do Programa de Pós-Graduação em Engenharia do Meio Ambiente da Universidade Federal de Goiás.

2e-mail : duaneizabel@gmail.com (D. I. Barbosa)

Aluna de do Programa de Pós-Graduação em Engenharia do Meio Ambiente da Universidade Federal de Goiás

3e-mail : alinearvelos@hotmail.com (A. A. Salgado)

Aluna de do Programa de Pós-Graduação em Engenharia do Meio Ambiente da Universidade Federal de Goiás

${ }^{4}$ e-mail : klebberformiga@gmail.com (K. T. M. Formiga)

Prof. Dr. da Escola de Engenharia Civil - Universidade Federal de Goiás - UFG.
} 


\section{INTRODUÇÃO}

O aumento das áreas impermeáveis nas regiões urbanas tem elevado o número de eventos de inundações e cheias. Tais eventos, associados à ineficiência e subestimação dos dispositivos de drenagem urbana, têm mostrado um cenário preocupante à sociedade.

O estudo das vazões decorrente de precipitações em centros urbanos depende, inicialmente, da quantificação das águas precipitadas para então, se adotar medidas que auxiliem no controle deste acréscimo, evitando a ocorrência das inundações.

A vazão de projeto constitui-se em dado fundamental para o dimensionamento de estruturas hidráulicas em obras de engenharia e na obtenção de cotas de alerta de inundações. Necessita-se, para sua determinação, de metodologias de cálculos confiáveis e seguras. Devido à carência de dados observados e ao elevado número de fatores intervenientes, opta-se por métodos indiretos, de formulação simples e que podem ser inadequados para as condições locais (STEFFEN e RONDON, 2000).

A inadequada aplicação de métodos indiretos no cálculo das vazões de projeto em bacias hidrográficas de pequeno porte, sem uma análise prévia da adequação dos parâmetros utilizados, pode causar transtornos às populações urbanas. Isto é agravado pelo crescimento exacerbado das cidades brasileiras e pela disposição inadequada de resíduos sólidos e objetos, que venham obstruir os canais de transporte e as galerias de águas pluviais.

O presente trabalho irá comparar duas metodologias distintas para determinação da vazão de projeto, de ampla utilização entre os órgãos municipais, estaduais e escritórios de consultoria, aplicados às pequenas bacias, método racional e tempo-área.

Para os métodos selecionados, destaca-se a necessidade de uma escolha criteriosa dos coeficientes, fórmulas e parâmetros, conduzindo a um dimensionamento adequado das estruturas hidráulicas. É de suma importância a validação dos resultados obtidos com observações in loco.

As bacias escolhidas para o estudo são consideradas de grande importância, pois englobam a região urbana e rural de Goiânia, que vem apresentando adiantado processo de degradação ambiental, devido à sua urbanização acelerada.

\section{2. ÁREA DE ESTUDO}

\subsection{BACIA DO CÓRREGO RUIVINHO}

A Bacia do Córrego Ruivinho, afluente do Córrego Barreiro, encontra-se na região sudeste do município de
Goiânia. O Córrego Barreiro é afluente da margem direita do rio Meia Ponte, um dos principais rios do Município.

O córrego Ruivinho nasce no interior do condomínio residencial Jardins Atenas ao lado do bairro Jardim Mariliza, com a extensão de 1,37 km, área drenante de $0,94 \mathrm{Km}^{2}$ e declividade média de $5 \%$ (Figura 01).

O uso e ocupação do solo no local é do tipo assentamento (edificações) e parcelamentos, principalmente por condomínios horizontais. A região ainda não se encontra totalmente urbanizada, mas, encontra-se em processo de expansão residencial e populacional.

\subsection{BACIA DO CORRÉGO MINGAU}

O Córrego Mingau, afluente do Córrego Cascavel, situado na região sul de Goiânia, apresenta área de drenagem de $2,45 \mathrm{Km}^{2}$, declividade média de $3,2 \%$ e comprimento de 1,31 km (Figura 01).

A área onde se situa o córrego Mingau é altamente adensada, onde o solo é ocupado por chácaras, lotes predominantemente com habitações, clube, comércio, oficina de pintura e funilaria, condomínio de sobrados, lotes vazios, horticultura, depósitos de caçambas de entulho, sendo a maioria com uso inadequado do solo (ASSUNÇÃO e SALES, 2007). São parcelamentos antigos, algumas possuem edificações em APP, porém há casos em que o recuo do talude, devido aos processos erosivos fluviais, avança sobre os terrenos, diminuindo a faixa de APP das propriedades.

Segundo Assunção (2002), o córrego Mingau encontra-se ameaçado pelos usos que se fazem em suas margens e no entorno, os quais favoreceram à vedação e canalização de suas principais nascentes, represamento para irrigação de hortaliças, lançamento de águas pluviais e de efluentes domésticos, dentre outros.

Assunção e Sales (2007) citam que a área é caracterizada ainda, pela presença de nascentes, lagos, represas, rios e similares, sendo considerada área de preservação permanente em que não pode haver ocupação nos seus 100 metros de raio ou 50 metros em cada margem, o que não ocorreu na área. De acordo com Assunção (2002), na época do plano inicial do loteamento do Parque Amazônia, onde está situado a nascente do córrego Mingau, já estava em vigor a legislação que previa a preservação permanente de florestas e demais formas de vegetação natural situadas nas nascentes e ao longos dos corpos hídricos. Porém essas medidas não foram tomadas no entorno do córrego.

\subsection{BACIA DO CORRÉGO DA CRUZ}

O Córrego da Cruz apresenta área de drenagem relativa à $0,66 \mathrm{~km}^{2}$ e está situado à $3 \mathrm{~km}$ a do Conjunto Vera Cruz - região oeste do município em questão, 
próximo à divisa com o município de Trindade. Está situado na zona rural do município de Goiânia. O comprimento do curso d'água é de 759,6 metros (Figura 01).
A área é basicamente constituída por pastagens, pois se encontra em zona rural, com ocorrência esparsa de algumas espécies arbóreas.

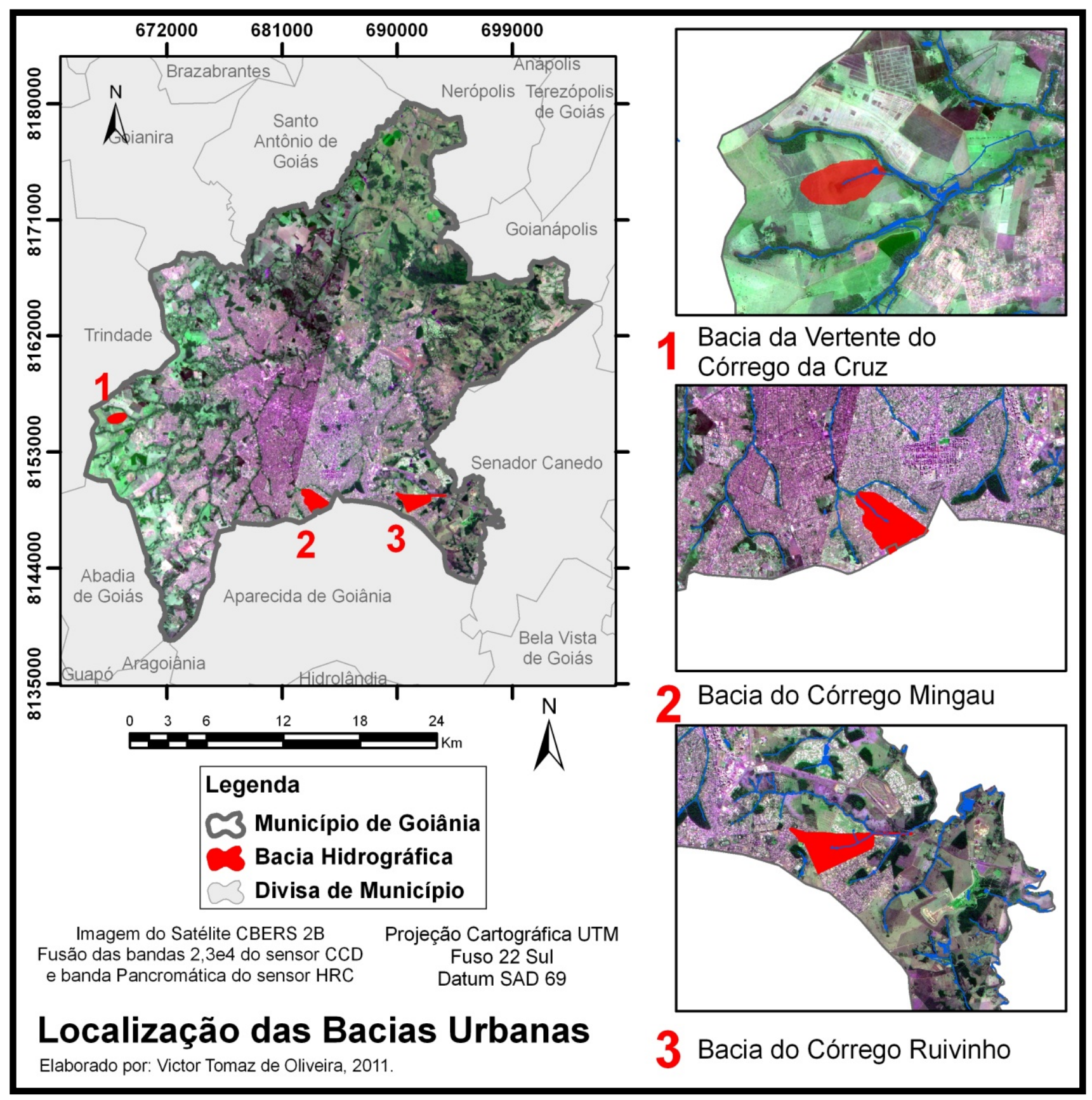

Figura 1: Mapa de localização das bacias estudadas no município de Goiânia - GO.

Fonte: SEIBT et al. (2012).

\section{MATERIAIS E MÉTODOS}

\subsection{MÉTODO RACIONAL}

Relaciona a precipitação com o deflúvio, considerando as principais características da bacia, tais como área, permeabilidade, forma, declividade média, sendo a vazão de dimensionamento calculada pela
Equação 1:

$$
\mathrm{Q}\left(\mathrm{m}^{3} / \mathrm{s}\right)=\mathrm{C} \times \mathrm{i}(\mathrm{mm} / \mathrm{h}) \times A\left(\mathrm{~m}^{2}\right)
$$

Os coeficientes de escoamento superficial foram adotados em função do tipo e uso do solo, considerando a urbanização futura da área são apresentados no Quadro 01. 
Quadro 01: Coeficientes de escoamento superficial adotados.

\begin{tabular}{|c|c|c|}
\hline Superfícies & Intervalo & C valor esperado \\
\hline Asfalto & $0,70-0,95$ & 0,83 \\
\hline Concreto & $0,80-0,95$ & 0,88 \\
\hline Calçadas & $0,75-0,85$ & 0,80 \\
\hline Telhado & $0,75-0,95$ & 0,85 \\
\hline Cobertura com solo arenoso (declividade de 2 a 7\%) & $0,10-01,5$ & 0,13 \\
\hline Cobertura com solo pesado (declividade de 2 a 7\%) & $0,18-0,22$ & 0,20 \\
\hline
\end{tabular}

Fonte: ASCE (1969).

\subsection{TEMPO DE CONCENTRAÇÃO}

Para a determinação dos tempos de concentração foram utilizadas as fórmulas de Kerby (Equação 2), Ven Te Chow (Equação 3) e U.S Corps Engineers (Equação 4).

$$
\begin{aligned}
& \text { Tc }=37\left(\frac{L \cdot a}{I}\right)^{0,47} \\
& \text { Tc }=25,2 \cdot\left(\frac{L}{\sqrt{I}}\right)^{0,64} \\
& \text { Tc }=0,30\left(\frac{L}{I^{1 / 4}}\right)^{0,76}
\end{aligned}
$$

Onde:

Tc = Tempo de concentração $(\min )$;

$\mathbf{L}=$ Comprimento $(\mathrm{km})$;

I = Declividade (\%);

$a=0,5$.

O tempo de concentração para fórmula do U.S Corps Engineers é dado em horas, multipilicando-se o resultado por 60 tem-se a resposta em minutos.

Com os três resultados obtidos para cada bacia, fez-se a média aritmética, para o tempo de concentração.

\subsection{INTENSIDADE PLUVIOMÉTRICA E CHUVA DE PROJETO}

Calculou-se a intensidade de chuva para o município de Goiânia para tempos de retorno de 2, 5, 10, 25 e 50 anos. As fórmulas da intensidade de chuva para o município de Goiânia são as seguintes (Costa, 1999):

\section{- Para 1 ano $\leq T \leq 8$ anos}

$$
i_{(\mathrm{mm} / \mathrm{min})}=\frac{56,8 \times\left(T_{(\text {anos })} 0,147+\frac{0,22}{T^{0,09}}\right)^{0,627}}{\left(t_{(\mathrm{min})}+24,8\right)^{0,975}}
$$

\section{- Para 8 anos $<T \leq 100$ anos}

$$
i_{(\mathrm{mm} / \mathrm{min})}=\frac{64,8 \times T_{(\mathrm{anos})}^{0,147}}{\left(t_{(\min )}+24,8\right)^{0,975}}
$$

As alturas de precipitação no período encontradas são então, colocadas de forma decrescente, partindo-se do intervalo de tempo central e colocandose as alturas seguintes alternadamente do lado esquerdo e direito deste intervalo. Ao método utilizado, dá-se o nome de Método dos Blocos Alternados (Tucci, 2007).

No método dos blocos alternados, os valores incrementais são reorganizados de forma que o máximo incremento ocorra, aproximadamente, no meio da duração da chuva total.

\subsection{MÉTODO TEMPO-ÁREA}

O Método Tempo-Área tem como ideia central a existência de isócronas no interior da bacia. As isócronas são linhas de contorno que unem pontos na bacia que estão separados do exutório pelo mesmo tempo de viagem. O tempo de viagem por sua vez é a diferença de tempo entre a ocorrência de escoamento em um elemento qualquer da bacia e a produção do efeito deste elemento na saída.

Para a determinação do gráfico tempo-área, empregou-se o tempo de concentração encontrado nas fórmulas citadas no item 3.2. Dividiu-se o tempo de concentração em 10 partes iguais, de modo, a representar melhor o comportamento da bacia. Construiu-se as isócronas no mapa da bacia, traçando os pontos de mesmo tempo de viagem dos locais de estudo, utilizando o software AutoCAD.

É importante ressaltar que as isócronas não podem se cruzar, fechar e só podem se originar e terminar no contorno da bacia. Esse método reflete diretamente o caminhamento ou translação da água na bacia.

Para determinar o diagrama Tempo-área foi utilizado o Método da Velocidade Média, apresentado 
por Singh (1988), que consiste em:

i. Definir uma malha de pontos, distribuídos uniformemente ao longo das curvas de níveis da bacia;

ii. Medir a distância de fluxo dos pontos até o canal do córrego;

iii. Calcular a velocidade média do fluxo de água para cada ponto até o canal utilizando o ábaco do U.S Department of Agriculture Soil Conservatio Service (1986), de acordo com o uso e a ocupação do solo verificado em cada bacia;

iv. Obter o tempo de viagem até o canal para cada ponto por meio da divisão da distância pela velocidade média;

v. Calcular o tempo de viagem no canal do córrego até o exutório, para cada ponto no canal;

vi. Executar o tempo de viagem de cada ponto que é obtido pela soma do tempo de viagem fora do canal mais o tempo de viagem no canal;

vii. Construir as isócronas com base nos tempos de viagem de cada ponto;

viii. Calcular das áreas das isócronas;

ix. Construir o diagrama Tempo-área.

Os tempos de viagem totais para cada ponto das isócronas foram determinados pela soma do tempo de viagem dentro e fora do canal. Foram identificados 12, 17 e 5 tempos de viagem para as bacias do Córrego Ruivinho, Mingau e da Cruz, respectivamente, os quais foram utilizados para traçar as isócronas.

As perdas do tempo-área foram definidas a partir do coeficiente de escoamento (C).

Inicialmente as curvas de níveis (de 5 em 5 metros) foram divididas em aproximadamente 10 pontos com mesmas distâncias entre si. Para isso foi utilizado o software Auto Cad. Depois dessa divisão, foram medidas as distâncias e a declividade de cada ponto até o canal do córrego.

A velocidade foi calculada por meio da Equação 7, apresentada por Tucci (2009), que relaciona o tipo de cobertura do solo na superfície da bacia - a, e a declividade em porcentagem - S, de cada ponto:

$$
V(\mathrm{~m} / \mathrm{s})=\frac{A\left(m^{2}\right) \times S}{2}
$$

A Tabela 01 apresenta valores de a de acordo com o tipo de cobertura do solo. Pelo fato da bacia estar inserida em uma área urbana adotou-se que a cobertura do solo é do tipo superfície pavimentada, cujo valor de a usado na fórmula é 0,610 . Em seguida foi calculado o
Tempo de viagem para cada ponto até o canal, pela divisão da distância pela velocidade até o canal.

Tabela 1: Tipo de cobertura

Tipo de cobertura

a

\begin{tabular}{cc} 
Tipo de cobertura & a \\
\hline Aloresta com solo coberto de folhagem & 0,076 \\
Pasto e grama & 0,143 \\
Solo quase nu & 0,216 \\
Canais com grama & 0,305 \\
Superfície pavimentada & 0,351 \\
& 0,610 \\
\hline
\end{tabular}

\section{RESULTADOS}

\subsection{MÉTODO RACIONAL}

Inicialmente foram obtidos os resultados do tempo de concentração utilizando as três fórmulas descritas no item 3.2, conforme Tabela 02.

As intensidades representam a variação da lâmina precipitada relativa aos respectivos tempos de retorno $(5,10,20,25$ e 50 anos), apresentado na Tabela 03.

\begin{tabular}{|c|c|c|c|}
\hline \multirow{2}{*}{ Fórmula } & \multicolumn{3}{|c|}{ Tempo de concentração (min) } \\
\hline & $\begin{array}{l}\text { Córrego } \\
\text { Ruivinho }\end{array}$ & $\begin{array}{l}\text { Córrego } \\
\text { Mingau }\end{array}$ & $\begin{array}{c}\text { Córrego da } \\
\text { Cruz }\end{array}$ \\
\hline (2) Kerby & 14,54 & 14,23 & 11,01 \\
\hline $\begin{array}{l}\text { (3) Ven Te } \\
\text { Chow }\end{array}$ & 18,42 & 17,90 & 12,62 \\
\hline $\begin{array}{l}\text { (4) U.S. Corps } \\
\text { Engineers }\end{array}$ & 16,84 & 16,28 & 10,75 \\
\hline Média & 16,60 & 16,14 & 11,46 \\
\hline
\end{tabular}

O tempo de concentração obtido na Tabela 02 representa a medida de tempo gasto para que toda a bacia contribua para o escoamento superficial nas seções consideradas. 
Posteriormente, foram encontradas as vazões para os coeficientes de escoamento de 0,3 a 0,9 . 0 Quadro 02 apresenta o aumento das vazões decorrente da elevação do coeficiente de escoamento, redução da infiltração e de chuvas com alto tempo de retorno, ou seja, chuvas intensas.

Tabela 3: Intensidades de chuva para as bacias e diferentes tempos de retorno

\begin{tabular}{|c|c|c|c|}
\hline \multirow{2}{*}{$\begin{array}{l}\text { Tempo de Retorno } \\
\text { (anos) }\end{array}$} & \multicolumn{3}{|c|}{ Intensidade de Chuva ( $\mathrm{mm} / \mathrm{min}$ ) } \\
\hline & Córrego Ruivinho & Córrego Mingau & Córrego da Cruz \\
\hline 2 & 1,76 & 1,77 & 2,00 \\
\hline 5 & 2,12 & 2,14 & 2,41 \\
\hline 10 & 2,39 & 2,42 & 2,72 \\
\hline 20 & 2,65 & 2,68 & 3,01 \\
\hline 25 & 2,74 & 2,77 & 3,11 \\
\hline 50 & 3,03 & 3,06 & 3,45 \\
\hline 2 & 1,76 & 1,77 & 2,00 \\
\hline
\end{tabular}

\begin{tabular}{|c|c|c|c|c|c|c|}
\hline & \multicolumn{6}{|c|}{$\begin{array}{l}\text { Quadro 2: Vazões das bacias para diferentes temp } \\
\text { coeficientes de escoamento. } \\
\text { Vazão }\left(\mathrm{m}^{3} / \mathrm{s}\right)\end{array}$} \\
\hline & 2 anos & 5 anos & 10 anos & 20 anos & 25 anos & 50 anos \\
\hline \multicolumn{7}{|c|}{ Córrego Ruivinho } \\
\hline 0,3 & 8,27 & 9,96 & 11,23 & 12,46 & 12,88 & 14,24 \\
\hline 0,4 & 11,03 & 13,29 & 14,98 & 16,61 & 17,17 & 18,99 \\
\hline 0,5 & 13,79 & 16,61 & 18,72 & 20,76 & 21,46 & 23,74 \\
\hline 0,6 & 16,54 & 19,93 & 22,47 & 24,91 & 25,76 & 28,48 \\
\hline 0,7 & 19,30 & 23,25 & 26,21 & 29,06 & 30,05 & 33,23 \\
\hline 0,8 & 22,05 & 26,57 & 29,95 & 33,21 & 34,34 & 37,98 \\
\hline 0,9 & 24,82 & 29,89 & 33,70 & 37,37 & 38,63 & 42,72 \\
\hline \multicolumn{7}{|c|}{ Córrego Mingau } \\
\hline 0,3 & 21,68 & 26,22 & 29,65 & 32,83 & 33,93 & 37,49 \\
\hline 0,4 & 28,91 & 34,95 & 39,53 & 43,77 & 45,24 & 49,98 \\
\hline 0,5 & 36,14 & 43,69 & 49,41 & 54,72 & 56,55 & 62,48 \\
\hline 0,6 & 43,37 & 52,43 & 59,30 & 65,66 & 67,87 & 74,97 \\
\hline 0,7 & 50,59 & 61,17 & 69,17 & 76,60 & 79,18 & 87,47 \\
\hline 0,8 & 57,82 & 69,91 & 79,05 & 87,55 & 90,49 & 99,96 \\
\hline 0,9 & 65,05 & 78,65 & 88,94 & 98,49 & 101,80 & 112,46 \\
\hline \multicolumn{7}{|c|}{ Córrego da Cruz } \\
\hline 0,3 & 6,64 & 7,99 & 9,02 & 9,99 & 10,32 & 11,45 \\
\hline 0,4 & 8,85 & 10,66 & 12,03 & 13,31 & 13,76 & 15,26 \\
\hline 0,5 & 11,06 & 13,33 & 15,04 & 16,64 & 17,20 & 19,08 \\
\hline 0,6 & 13,27 & 15,99 & 18,05 & 19,97 & 20,63 & 22,89 \\
\hline 0,7 & 15,48 & 18,66 & 21,06 & 23,30 & 24,07 & 26,71 \\
\hline 0,8 & 17,69 & 21,32 & 24,06 & 26,63 & 27,51 & 30,52 \\
\hline 0,9 & 19,91 & 23,99 & 27,07 & 29,96 & 30,95 & 34,34 \\
\hline
\end{tabular}

No caso dos mananciais urbanos o escoamento é reforçado pela elevada taxa de impermeabilização das áreas urbanas e pelos sistemas de coleta das águas pluviais, que diminui a alimentação do lençol freático, aumentando o coeficiente de escoamento superficial, mesmo nos córregos naturais. Para bacias com semelhanças físicas como o Córrego Ruivinho e o Córrego da Cruz os resultados foram bem aproximados.

\subsection{MÉTODO TEMPO-ÁREA}

As isócronas foram traçadas unindo pontos com mesmo tempo de viagem, ou seja, para a Bacia do Córrego Ruivinho foram obtidas 12 isócronas, com tempo de concentração variando 3,7 minutos cada, totalizando em 44 minutos o tempo de concentração total para a bacia; para o Córrego Mingau foram 17 isócronas com tempo de concentração variando 3,8 
minutos cada, totalizando 64,4 minutos para o tempo de concentração total da bacia, e para o Córrego da Cruz foram 5 (cinco) isócronas e o tempo de concentração teve variação de 5,2 minutos em cada, sendo o tempo de concentração total da bacia de 26 minutos, conforme a Figura 02.

A diferença entre os tempos de concentração obtidos com o método racional e o método Tempo-área, ocorre, pois, método Tempo-área baseia-se no estabelecimento de uma função relacionando áreas de contribuição na bacia ao tempo necessário para que essas áreas contribuam à formação de vazões à saída da bacia. Já no método racional a distribuição da precipitação é uniforme, no tempo e no espaço;

Foram calculadas as áreas de cada isócrona e correlacionou-se cada área com um tempo de concentração, área (A1) com tempo de concentração (tc1) e assim, sucessivamente, para todas as demais áreas e tempos de concentração.
De acordo com as Figuras 03, 04 e 05 percebese que o método tempo-área pode assumir a distribuição uniforme da precipitação no espaço, assim como, a intensidade da precipitação pode variar no tempo. A duração da precipitação usualmente excede o tempo de concentração da bacia; tornando o escoamento em redes de cursos d'água e canais relevantes. Os efeitos de armazenamento superficial, durante o escoamento, são desprezíveis, pois não ocorre efeito de enchimento, ou seja, tudo que entra na bacia, sai imediatamente.

No primeiro intervalo de tempo do bloco 1 das precipitações atinge todas as bacias, mas apenas os escoamento superficiais provenientes das primeiras subáreas concentram-se à saída da bacia.

A partir do segundo intervalo de tempo, os escoamento superficiais provenientes das segundas subáreas, decorrentes da primeira parte de precipitação concentram-se às saídas das bacias. A essas contribuições somam-se os escoamentos superficiais provenientes das primeiras sub-áreas, decorrentes da segunda parte da precipitação.

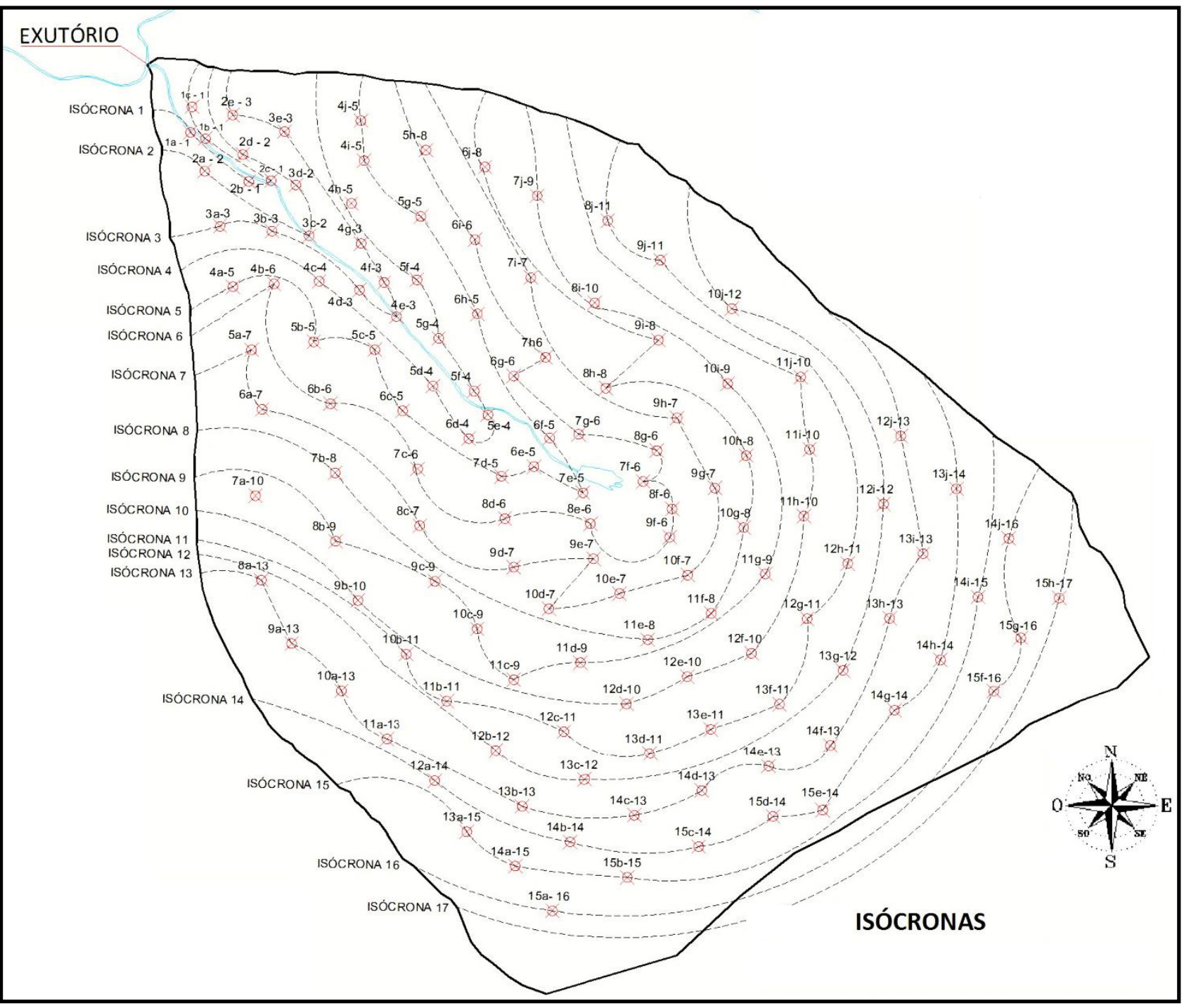

Figura 2: Isócronas do Córrego Mingau.

Fonte: SEIBT et al. (2012). 


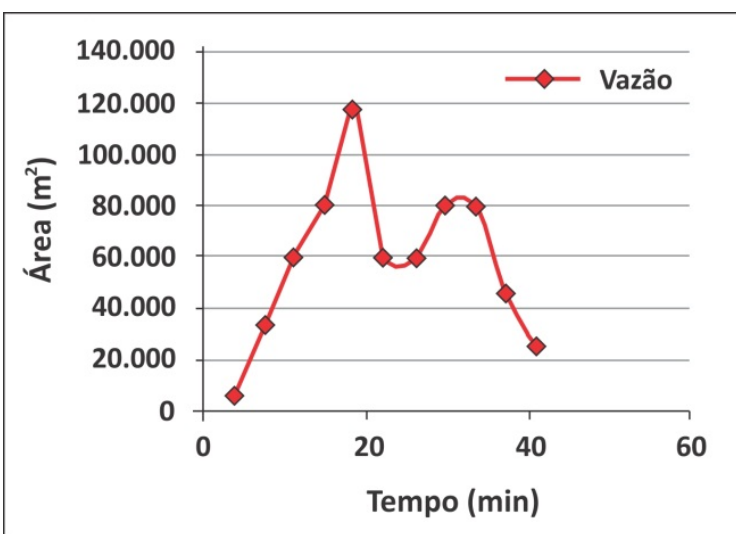

Figura 3: Método tempo-área - Córrego Ruivinho.

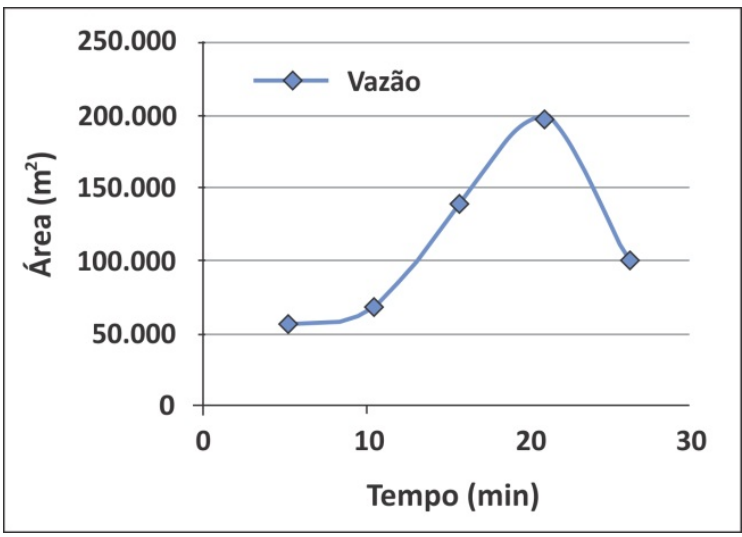

Figura 4: Método tempo-área - Córrego da Cruz.

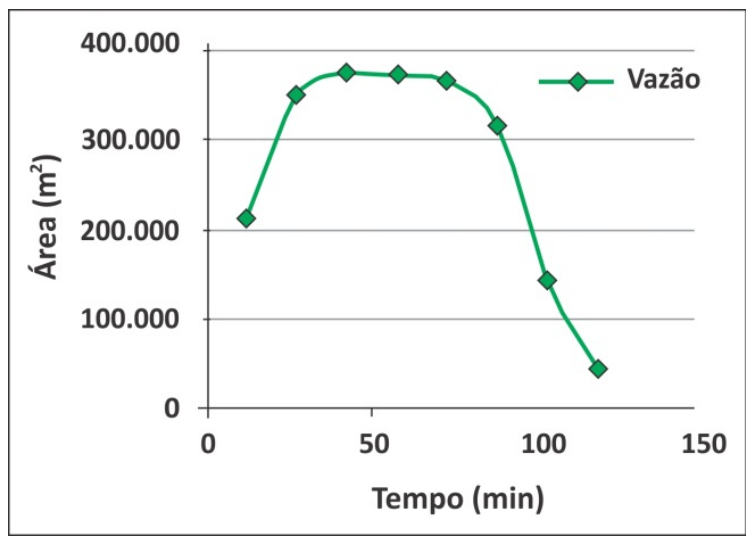

Figura 5: Método tempo - área - Córrego Mingau.

As Figuras 06, 07 e 08 correspondem às chuvas de projeto para as bacias estudadas. Percebe-se que a precipitação produz um hidrograma de cheia com característica de hidrograma unitário e possui intensidade constante no tempo. Essa precipitação é uniformemente distribuída em toda a bacia hidrográfica e, portanto, gera escoamento superficial generalizado.

O hidrograma resultante da ocorrência de uma precipitação como as descritas abaixo (precipitação de duração unitária $\tau$ ) reflete o conjunto das características morfológicas, de tipo e uso do solo da bacia.

Os tempos característicos da chuva de projeto (tempo de subida, tempo de recessão e tempo de base) são sempre constantes.

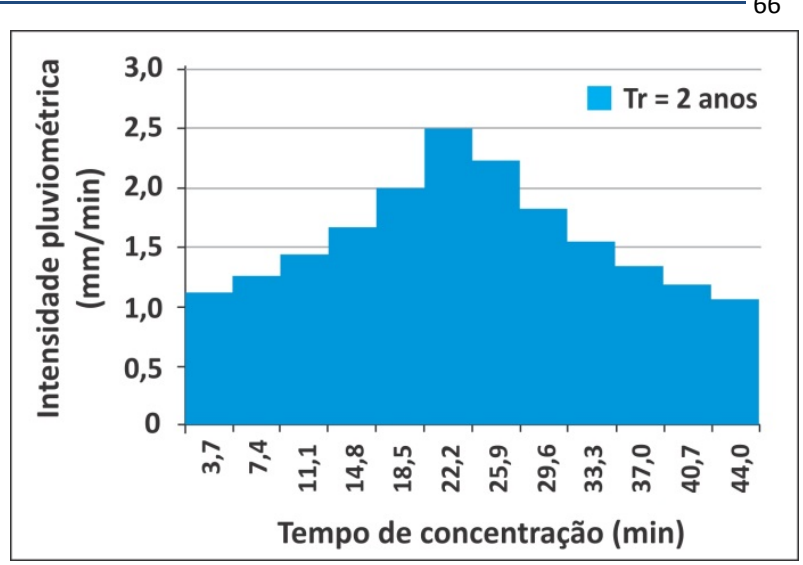

Figura 6: Hietograma de projeto - Córrego Ruivinho Tempo de retorno 2 anos.

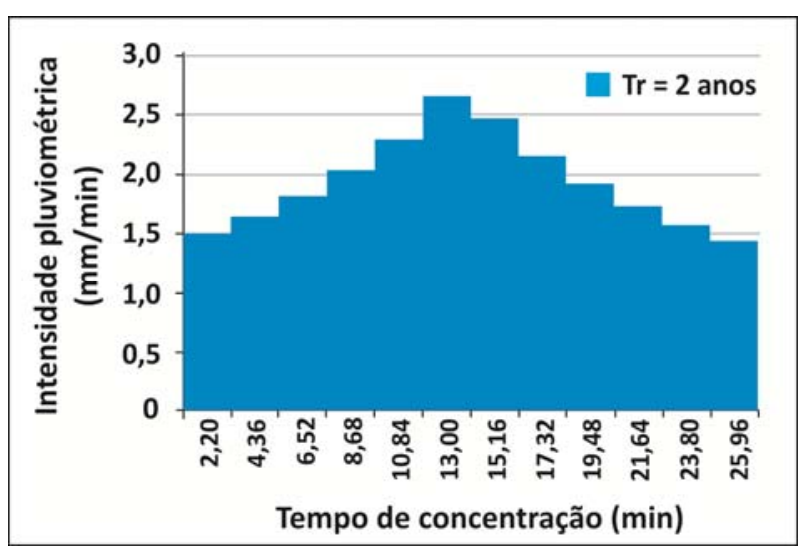

Figura 7: Hietograma de projeto - Córrego da Cruz Tempo de retorno 2 anos.

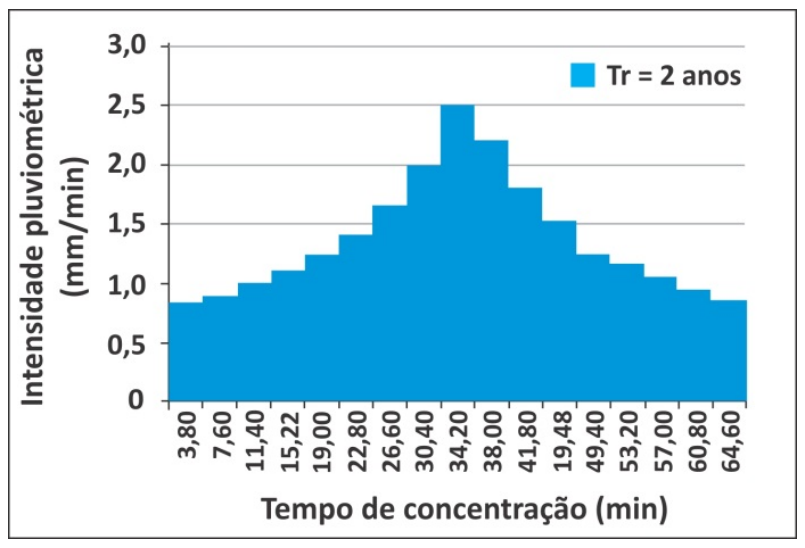

Figura 8: Hietograma de projeto - Córrego Mingau Tempo de retorno 2 anos

Os resultados obtidos pelo método tempo área seguem no Quadro 03. Percebe-se que as vazões encontradas, assim como pelo método racional, elevaram-se conforme o aumento no tempo de retorno e do coeficiente de escoamento.

Por meio das isócronas, os tempos de concentrações obtidos para as bacias foram de 44, 26, e 64,4 minutos para o córrego Ruivinho, da Cruz e Mingau, respectivamente. 


\begin{tabular}{|c|c|c|c|c|c|c|}
\hline \multicolumn{7}{|c|}{ Córrego Ruivinho } \\
\hline $\begin{array}{c}\text { Coeficientes } \\
\text { de } \\
\text { escoamento }\end{array}$ & $\begin{array}{c}\mathrm{Q}\left(\mathrm{m}^{3} / \mathrm{s}\right) \\
\text { para } \operatorname{Tr}=2 \\
\text { anos }\end{array}$ & $\begin{array}{c}Q\left(\mathrm{~m}^{3} / \mathrm{s}\right) \\
\text { para } T r=5 \\
\text { anos }\end{array}$ & $\begin{array}{c}\mathrm{Q}\left(\mathrm{m}^{3} / \mathrm{s}\right) \\
\text { para } \mathrm{Tr}=10 \\
\text { anos }\end{array}$ & $\begin{array}{c}Q\left(\mathrm{~m}^{3} / \mathrm{s}\right) \\
\text { para } \operatorname{Tr}=20 \\
\text { anos }\end{array}$ & $\begin{array}{c}Q\left(\mathrm{~m}^{3} / \mathrm{s}\right) \\
\text { para } \operatorname{Tr}=25 \\
\text { anos }\end{array}$ & $\begin{array}{c}\mathrm{Q}\left(\mathrm{m}^{3} / \mathrm{s}\right) \\
\text { para } \mathrm{Tr}=50 \\
\text { anos }\end{array}$ \\
\hline 0,3 & 8,22 & 9,90 & 11,16 & 12,37 & 12,79 & 14,15 \\
\hline 0,4 & 10,96 & 13,20 & 14,88 & 16,50 & 17,06 & 18,86 \\
\hline 0,5 & 13,69 & 16,50 & 18,60 & 20,62 & 21,32 & 23,58 \\
\hline 0,6 & 16,43 & 19,79 & 22,32 & 24,74 & 25,58 & 28,29 \\
\hline 0,7 & 19,17 & 23,09 & 26,04 & 28,87 & 29,85 & 33,01 \\
\hline 0,8 & 21,91 & 26,39 & 29,75 & 32,99 & 34,11 & 37,72 \\
\hline 0,9 & 24,65 & 29,69 & 33,47 & 37,12 & 38,38 & 42,44 \\
\hline \multicolumn{7}{|c|}{ Córrego Mingau } \\
\hline 0,3 & 19,88 & 24,03 & 27,18 & 30,1 & 31,11 & 34,37 \\
\hline 0,4 & 26,5 & 32,05 & 36,24 & 40,13 & 41,48 & 45,82 \\
\hline 0,5 & 33,13 & 40,06 & 45,3 & 50,16 & 51,85 & 57,28 \\
\hline 0,6 & 39,76 & 48,07 & 54,36 & 60,2 & 62,22 & 68,73 \\
\hline 0,7 & 46,38 & 56,08 & 63,42 & 70,23 & 72,59 & 80,19 \\
\hline 0,8 & 53,01 & 64,09 & 72,48 & 80,26 & 82,96 & 91,64 \\
\hline 0,9 & 59,64 & 72,1 & 81,54 & 90,3 & 93,33 & 103,1 \\
\hline \multicolumn{7}{|c|}{ Córrego da Cruz } \\
\hline 0,3 & 6,63 & 7,99 & 9,02 & 9,98 & 10,32 & 11,44 \\
\hline 0,4 & 8,85 & 10,66 & 12,03 & 13,31 & 13,75 & 15,26 \\
\hline 0,5 & 11,06 & 13,32 & 15,04 & 16,64 & 17,19 & 19,07 \\
\hline 0,6 & 13,27 & 15,99 & 18,04 & 19,97 & 20,63 & 22,89 \\
\hline 0,7 & 15,48 & 18,65 & 21,05 & 23,3 & 24,07 & 26,7 \\
\hline 0,8 & 17,69 & 21,32 & 24,06 & 26,62 & 27,51 & 30,52 \\
\hline 0,9 & 19,9 & 23,98 & 27,07 & 29,95 & 30,95 & 34,33 \\
\hline
\end{tabular}

Pela análise dos resultados e comparação dos métodos, percebe-se que o método racional não se aplica a bacias hidrográficas com áreas de drenagem superiores a $1 \mathrm{~km}^{2}$. Por isso, a discrepância na diferença dos resultados, principalmente para a bacia do Córrego Mingau, que apresenta a maior área. Conforme os dados demonstrados, podemos afirmar que os métodos adotados apresentaram valores diferentes para bacias com áreas superiores a $1 \mathrm{Km}^{2}$.

O método tempo-área é uma extensão do método racional podendo, entretanto, considerar variações de intensidade da precipitação ao longo do tempo e maior diversidade de uso do solo na bacia hidrográfica. Esse método baseia-se no estabelecimento de uma função relacionando áreas de contribuição na bacia ao tempo necessário para que essas áreas contribuam à formação de vazões à saída da bacia (PONCE, 1989).

\section{CONCLUSÕES}

O método Racional foi o que apresentou os maiores valores de vazão, independente do período de retorno, para as 3 bacias em estudo. Visualizou-se que o método racional tende a superestimar as vazões, devido as suas limitações, como a distribuição temporal das vazões. 
Conclui-se que o método tempo-área permite a discretização da área, de modo a determinar a ocupação de cada parte da bacia e o seu respectivo tempo de chegada à foz. Para bacias que apresentam área em torno de $1 \mathrm{~km} 2$, a fórmula racional aumento em $8 \%$ a vazão, para as bacias menores essa diferença foi insignificante.

Não é possível recomendar com absoluta certeza, um método mais apropriado para a bacia, tendo em vista os resultados encontrados e a indisponibilidade de dados observados para comparação. Porém, o método de simulação utilizado na obtenção do hidrograma, tem demonstrado representar de forma satisfatória o escoamento superficial em bacias hidrográficas, desde que os coeficientes de rugosidade e os parâmetros físicos, sejam escolhidos de forma apropriada.

\section{REFERÊNCIAS BIBLIOGRÁFICAS}

ASCE. Design and construction of sanitary and storm sewers . Manuals and Reports of Engineering Pratice № 37. New York.1969.

ASSUNÇÃO, S.G.S. Riscos ambientais da ocupação urbana no entorno de águas superficiais - $O$ caso do córrego Mingau, no bairro Parque Amazônia, em Goiânia - GO. Dissertação de mestrado 2002

BRASIL. Departamento Nacional de Infraestrutura de Transportes. Diretoria de Planejamento e Pesquisa. Coordenação Geral de Estudos e Pesquisa. Instituto de Pesquisas Rodoviárias. Manual de hidrologia básica para estruturas de drenagem. -2a ed. - Rio de Janeiro, 2005. 133 p.

BRASIL. Secretaria Nacional de Saneamento Ambiental Gestão de águas pluviais urbanas/ Tucci, Carlos. E.M - Brasília: Ministério das Cidades, 2006. 194 p. (Saneamento para todos; 4 ㅇvolume).

CAMPOS, J. E. G., et al. Diagnóstico Hidrogeológico da Região de Goiânia. AGIM/GO Superintendência de Geologia e Mineração da Secretaria da Indústria e Comércio, Goiânia, GO, 2003, 125 pp.

COSTA, A. R.; SIQUEIRA, E. Q.; MENEZES FILHO, F. C. M. Curso Básico de Hidrologia Urbana: nível 3. Brasília. ReCESA, 2007. $130 \mathrm{p}$.

GOIÂNIA. Prefeitura de Goiânia. Agência Municipal de Meio Ambiente. Gerência de Contenção e Recuperação de Erosões e Afins. Diagnóstico Ambiental do Córrego Mingau. Ozana, Hérica et al. 2009.

GOIÂNIA. Prefeitura de Goiânia. Agência Municipal de Meio Ambiente. Gerência de Contenção e Recuperação de Erosões e Afins. Diagnóstico Ambiental do Córrego Barreiro. Ribeiro, Márcio Gabriel Nunes et al. 2009.

MAYS, L.W. Water resources engineering - 2005 ed. Wiley

PONCE, V. M. Engineering Hydrology, Principles and Practices. Prentice-Hall, Englewood Cliffs, New Jersey, 1989.
PORTO, R.L et al. Escoamento Superficial (Análise do Hidrograma, Hidrograma Unitário). Escola Politécnica da USP Departamento de Engenharia Hidráulica e Sanitária. São Paulo, 1999.

SALES, S.G.S; ASSUNÇÃO, M.P. Análise do risco de danos às águas subterrâneas provocados por usos antrópicos no entorno do Córrego Mingau, no Parque Amazônia, em Goiânia - GO. In Anais do XVII Simpósio Brasileiro de Recursos Hídricos, São Paulo - SP, 2007

SINGH, V. J; Hydrologic Systems Rainfall-Runoff Modeling, Volume I, Englewood Clifes: Prentice Hall, 1988.

STEFFEN, J. L; RONDON, M.A.C. Determinação da vazão de projeto em bacias urbanas. In Anais do XXVII Congresso Interamericano de Engenharia Sanitária e Ambiental. Porto Alegre - RS, 2.000 .

TUCCI, C. E. M; SILVEIRA, A. L. L. et al. Hidrologia Ciência e Aplicação, 4.ed. 1 reimp. Porto Alegre, RS: Editora da UFRGS/ABRH, 2009. 